\title{
IMPLEMENTASI IoT(Internet Of Things) MONITORING KUALITAS AIR DAN SISTEM ADMINISTRASI PADA PENGELOLA AIR BERSIH SKALA KECIL
}

\author{
Fitri Febrianti, Suryo Adi Wibowo, Nurlaily Vendyansyah \\ Program Studi Teknik Informatika S1, Fakultas Teknologi Industri \\ Institut Teknologi Nasional Malang, Jalan Raya Karanglo km 2 Malang, Indonesia \\ 1718002@schoolar.itn.ac.id
}

\begin{abstract}
ABSTRAK
Kebutuhan air bersih untuk masyarakat Indonesia sangatlah penting. Baik itu digunakan untuk air minum , memasak, mandi dan mencuci. Namun kebutuhan air bersih ini sangat sulit di penuhi di daerah yang jauh dari sumber mata air, terlebih lagi sumur-sumur milik pribadi. Kebanyakan sumber air yang diperoleh dari sumur sering sekali keruh dan $\mathrm{pH}$ airnya tidak sesuai dari batas nomal. Salah satunya di desa Pangkalan lada, Kalimantan Tengah. Masih banyak penduduknya menggunakan sumur tadah hujan yang kualitas airnya tidak selau baik. Dengan adanya masalah tersebut, solusi yang dapat di terapkan adalah monitoring kualitas air untuk menetukan baik buruknya kualitas air agar bisa digunakan oleh masyarakat. Dikembangkan implementasi IoT (internet of things) monitoring kualitas air dan sistem administrasi pada pengelola air bersih skala kecil yang menampilkan keadaan secara visual pada fitur monitoring dapat dikendalikan secara efisien dengan media wireless melalui website. Disamping itu dengan ditambahkannya sebuah sensor untuk mendeteksi kadar $\mathrm{pH}$ air dan penyaringannya dapat membantu penduduk yang sulit mendapatkan air bersih maupun menetukan bahwa air tersebut layak tidaknya untuk di konsumsi. Serta menampilkan biaya penggunaan PDAM dalam kurun waktu bulanan pada website monitoring yang didapatkan dari data sensor flow meter. Pengembangan ini termasuk dalam pengelolaan Smart City skala kecil, karena pengembangan alat ini membantu penduduk untuk lebih moderenisasi alat-alat dalam kehidupan sehari- hari . Dari Implementasi IoT (internet of things) monitoring kualitas air dan sistem administrasi dilakukan pengujian pada Setiap alat yang dilakukan pada setiap sensor yang di gunakan pada tiap alat. Diperoleh Hasil pengujian menunjukkan bahwa sensor $\mathrm{pH}$ didapatkan nilai 7.00 untuk air mineral, air lemon 5.9, air sabun 10.4, dan dengan indikasi lakmus dalam penentuan asam basa pada air. Pengujian diperoleh pada sensor turbidity terhadap air bersih didapatkan nilai rata-rata error $0.12 \%$, teh $0.02 \%$, dan air kopi $0.08 \%$.
\end{abstract}

Kata kunci : Internet of Things, monitoring kualitas air, Administrasi,pH meter, turbidity,flow meter, Arduino uno,Smart City, ESP8266.

\section{PENDAHULUAN}

Kebutuhan air bersih untuk masyarakat Indonesia sangatlah penting. Baik itu digunakan untuk air minum, memasak, mandi dan mencuci. Namun kebutuhan air bersih ini sangat sulit di penuhi di daerah yang jauh dari sumber mata air, terlebih lagi sumursumur milik pribadi. Kebanyakan sumber air yang diperoleh dari sumur sering sekali keruh dan $\mathrm{pH}$ airnya tidak sesuai dari batas nomal. Salah satunya di desa Pangkalan lada , Kalimantan Tengah. Masih banyak penduduknya menggunakan sumur tadah hujan yang kuaitas airnya tidak selalu baik. Selain masalah dari sumur air pribadi pada PDAM juga sering terjadi masalah air yang keruh akibat pipa penyalur di dalam tanah pecah atau rusak, maka air yang tersalur ke rumah-rumah penduduk keruh bercampur tanah. Semakin jauh jarak rumah dari sumber air PDAM semakin banyak masalah pada air yang di salurkan.

Jika kadar pH terlalu jauh di luar skala, bisa saja tidak aman bagi tubuh. Selain masalah $\mathrm{pH}$ air yang layak digunakan merupakan air yang bersih tidak keruh. Cara mengatasi air keruh bisa dilakukan penyaringan sederhana menggunakan bahan-bahan alami seperti arang, sabut kelapa , kerikil , dan pasir halus. Bahan - bahan alami ini sangat mudah ditemukan di lingkungan sekitar kita, jadi sangat mudah dalam proses pembuatannya. Selain itu pada penyaluran air PDAM ke rumah-rumah penduduk alat ukurnya masih menggunakan manual, di era modern sekarang ini alat yang dibutuhkan sudah berbasis digital. Agar lebih mudah dalam pendataannya dan lebih akurat untuk nilai yang didapatkan maka digunakan sensor flow meter guna menentukan debit air yang masuk ke tiap-tiap rumah penduduk untuk diubah ke rupiah untuk pembayaran perbulannya.

Dengan demikian dikembangkan implementasi IoT(internet of things) monitoring kualitas air dan sistem administrasi pada pengelola air bersih skala kecil yang menampilkan keadaan secara visual pada fitur monitoring dapat dikendalikan secara efisien dengan media wireless melalui website. Disamping itu dengan ditambahkannya sebuah sensor untuk mendeteksi kadar $\mathrm{pH}$ air dan penyaringannya dapat membantu penduduk yang sulit mendapatkan air bersih maupun menetukan bahwa air tersebut layak tidaknya untuk di konsumsi. Serta menampilkan biaya penggunaan PDAM dalam kurun waktu bulanan pada website monitoring yang didapatkan dari data sensor flow meter. Pengembangan ini termasuk dalam pengelolaan Smart City skala kecil, karena pengembangan alat ini membantu penduduk untuk 
lebih moderenisasi alat-alat dalam kehidupan seharihari .

\section{TINJAUAN PUSTAKA}

\subsection{Penelitian Terdahulu}

Suryo Adi Wibowo Berdasarkan penelitian yang dilakukan oleh Joseph Dedy Irawan, Sonny Prasetio, Suryo Adi Wibowo, dilakukan penelitian tentang Early warning system for building automation system. dalam penelitian ini peralatan yang digunakan untuk memantau dan mengeksekusi perintah adalah Programmable Logic Control (PLC), dengan menggunakan PLC sebagai perangkat kontrol dapat dibuat sistem peringatan dini, di mana sistem akan mendeteksi beberapa sensor yang akan menginformasikan pemilik melalui SMS jika ada kasus gangguan di rumah [1]

Dewi Lestari mengembangkan sistem pengendalian air PDAM dengan arduino uno yang menggunakan sensor flow meter untuk pengukuran volume dan debit air, pompa air serta LCD untuk tampilan volume air dan debit air. Sehingga dapat diketahui dalam sehari berapa banyak liter air yang digunakan untuk kebutuhan hidup. Berdasarkan hasil pengujian, didapatkan nilai accurancy untuk volume sebesar $95.6 \%$ - $96.8 \%$ yaitu dengan membandingkan nilai volume pembaca di arduino dan volume perhitungan manual dan nilai accurancy untuk debit air adalah $95.6 \%$. Sehingga dapat dikatakan semakin tinggi nilai flowrate maka nilai error semakin kecil dan sebaliknya semakin rendah nilai flowrate maka nilai error semakin besar. [2]

Kurniatuty melakukan pengembangan rancang bangun sistem kontrol pakan ikan dan kekeruhan air yang di lengkapi dengan monitoring kualitas air berbasis internet of things. Sistem ini bekerja saat jadwal pemberian pakan ikan yang telah ditentukan kemudian servo membuka penutup wadah dan mengirimkan laporan sisa pakan ke website, ketika sensor mendeteksi tingkat kekeruhan melebihi 25NTU relay akan mengaktifkan solenoid valve untuk menguras isi air kemudian bila batas air sudah dicapai solenoid akan menutup dan pompa air akan menyala kemudian mengirim laporan ke website, Sensor $\mathrm{pH}$ membaca kondisi $\mathrm{pH}$ air kemudian mengirimkan laporan ke website, Sensor suhu membaca kondisi suhu air kemudian mengirimkan laporan ke website. Sebelum semua data dikirim ke website data diolah terlebih dahulu pada arduino kemudian proses pengiriman data secara real time ke webstite melalui modul wifi. [3].

Sedangkan Ummi Syafiqoh melakukan pengembangan wireless sensor network berbasis internet of things untuk system pemantauan kualitas air dan tanah pertanian. Beranggapan bahwa air sangat penting bagi semua aspek kehidupan di bumi ini. Diantaranya adalah dalam bidang pertanian, air digunakan dalam proses fotosintesis tanaman. Pada lahan pertanian, penggunaan pupuk sangatlah berpengaruh untuk memperkaya unsur hara dalam tanah sehingga menyuburkan tanaman. Akan tetapi di sisi lain penggunaan pupuk secara terus menerus juga memiliki dampak negatif terhadap kualitas air dan tanah pertanian, diantaranya dapat mengubah $\mathrm{pH}$ tanah dan mengganggu keseimbangan unsur hara dalam tanah. Oleh karena itu kualitas air dan tanah pada lahan pertanian merupakan salah satu hal penting yang perlu mendapat perhatian khusus dalam pengelolaannya. Salah satu solusi agar kualitas air dan tanah dapat dipantau dan dikelola dengan efisien adalah dengan memanfaatkan Wireless Sensor Network (WSN) berbasis Internet of Things. Teknologi WSN dapat digunakan untuk memonitor beberapa hal seperti temperatur, kelembaban, kondisi cahaya, level derau, pergerakan suatu objek dan lain sebagainya [4]

Diko Susanto, mengembangkan alat penyaring air kotor menjadi air bersih menggunakan mikrokontroler ATMEGA32. Ada berbagai macam cara sederhana yang dapat digunakan untuk mendapatkan air bersih, dan cara yang paling umum digunakan adalah dengan membuat saringan air, dan bagi kita mungkin yng paling tepat adalah membuat penjernih air atau saringan air sederhana. Perlu diperhatikan, bahwa penyaringan air secara sederhana tidak dapat menghilangkan sepenuhnya garam yang terlarut di dalam air. Karena pengolahan air kotor menjadi air bersih harus dilakukan secara teliti agar kuman yang ada pada air benar-benar sudah tidak ada [5]

\subsection{IoT(Internet Of Things)}

Pada penelitiannya Shidiq menjelaskan tentang pengertian IoT "Thing” pada konteks IoT dapat berupa perangkat apa saja dengan sendor internal apa pun yang memiliki kemampuan untuk mengumpulkan dan mentransfer data melalui jaringan tanpa intervensi manual. Teknologi tertanam dalam objek membantu perangkat IoT untuk berinteraksi dengan keadaan internal dan lingkungan eksternal, yang pada gilirannya membantu dalam proses pengambilan keputusan. Singkatnya, IoT adalah konsep yang menghubungkan semua perangkat ke internet dan memungkinkan perangkat IoT berkomunikasi satu sama lain melalui internet. IoT adalah jaringan raksasa dari perangkat yang tehubung - semua yang mengumpulkan dan membagikan data tentang bagaimana suatu perangkat tersebut digunakan dan lingkungan dimana perangkat tersebut di operasikan. [6]

\subsection{Smart City}

Smart City pada hakekatnya adalah CyberPhysicalSocial systems dalam lingkup kota, yakni sebuah sistem yang mengintegrasikan sistem fisik kota, sistem sosial, dan sistem digital melalui media siber (Internet). Sistem fisik kota mencakup berbagai sarana-prasarana pendukung kehidupan kota, seperti: gedung, jembatan, jaringan listrik, sungai, jalan, kantor, stasiun, terminal, bandara, infrastruktur komunikasi, dan lain-lain. Sementara sistem sosial 
kota mencakup berbagai lingkungan manusia dan individu yang ada di dalam kota mencakup pemerintah kota, komunitas, keluarga, pasar, masyarakat umum, maupun individu warga kota. Sedangkan sistem digital kota mencakup sensor, jaringan komputer, komputasi, dan kontrol, data center, dan lain-lain.

Cyber-Physical-Social systems sebuah Smart City mirip dengan sistem tubuh manusia. Kecerdasan membutuhkan media input. Panca indera tubuh manusia (mata, telinga, hidung, lidah, dan kulit) adalah media "perasa", penangkap, dan pengumpul masukan (input) bagi kecerdasan manusia, sementara dalam sistem Smart City fungsi media input ini dilakukan oleh CCTV dan sensor yang dipasang di berbagai komponen kota seperti CCTV lalu lintas, CCTV analitik obyek, sensor ketinggian air sungai, sensor polusi udara dan air, sensor kepadatan lalu lintas, sensor suara untuk mengukur kegaduhan suatu area, sensor cahaya untuk lampu penerangan otomatis, sensor suhu, sensor kecepatan kendaraan yang melintas, sensor load cell untuk mengukur beban obyek yang melintas jembatan, dan sensor tekanan untuk mengukur. Sementara analogi otak manusia untuk memproses dan menyimpan data-data masukan dari panca indera dalam sistem Smart City dapat dilakukan prosesor, mikrokontroler, Digital/Network Video Recorder, Hard disk, maupun SD card. Respon dari hasil pemroses data input dalam analogi tubuh manusia dapat berupa ucapan atau gerakan tubuh, sementara dalam sistem otomatisasi Smart City dapat berupa tampilan informasi di LCD, luaran suara di speaker atau berupa luaran gerak yang dilakukan oleh aktuator. [7]

\subsection{Website}

Website adalah kumpulan halaman web yang saling terhubung didalam suatu domain atau sub domain tertentu yang menyediakan informasi yang bisa diakses oleh pengguna lewat server lokal maupun server online. Website biasanya dibuat untuk memberikan informasi dalam hal tertentu pada pengguna, namun seiring perkembangan jaman website kini juga bisa digunakan untuk situs jual beli barang secara online, bahkan pusat monitoring dan pengendali alat berbasis IoT (Internet Of Thing). [8]

\subsection{Arduino Uno}

Arduino Uno adalah IC mikrokontroler keluaran ATMEL AVR sebagai otak/processor dan menggunakan Arduino IDE sebagai software pemrogramannya. IC yang digunakan IC AVR tipe ATMEGA328 sebagai mikrokontrolernya. Arduino Uno memiliki 14 pin I/O digital dan 6 pin I/O analog. Untuk menghubungkan Arduino ke computer menggunakan kabel converter USB type A atau B sama seperti yang digunakan USB printer. [9]

\subsection{Modul Sensor $\mathrm{pH}$ air}

Modul sensor ini merupakan module yang berfungsi untuk mendeteksi tingkat $\mathrm{pH}$ air yang dimana outputnya berupa tegangan analog. Sehingga untuk mengkonversi nilai pembacaan harus dimasukan ke dalam rumus di kode program yang dibuat. Dikarenakan module ph meter sensor ini range output tegangan analognya dari $0-3 \mathrm{Vdc}$ dengan inputan power supply $3.3-5.5 \mathrm{Vdc}$. [10]

\subsection{Sensor Turbidity}

Analog Turbidity yang berfungsi mengukur kualitas tingkat kekeruhannya. Sensor ini mendeteksi partikel tersuspensi dalam air dengan cara mengukur transmitansi dan hamburan cahaya yang berbanding lurus dengan kadar Total Suspended Solids (TTS). Semakin tinggi kadar TTS, semakin tinggi tingkat kekeruhan air tersebut.Sensor ini dapat digunakan menggunakan pin Analog ataupun digital sehingga dapat digunakan lebih mudah pada Ardunio atau mikrokontroler lainnya..Sensor ini dapat diaplikasikan untuk mengukur tingkat kekeruhan air pada sungai, danau, laboraturium, limbah cair. [11]

\subsection{Buzzer}

Buzzer merupakan komponen elektronika yang cara kerjanya mengubah sinyal listrik menjadi getaran suara/bunyi. Komponen yang satu ini sering digunakan pada alat-alat untuk keperluan notifikasi atau pemberitahuan. Buzzer mempunyai 2 jenis yaitu buzzer aktif dan buzzer pasif. Buzzer aktif merupakan jenis buzzer yang dapat mengeluarkan suara sendiri, jadi ketika langsung di beri tegangan akan langsung bunyi. Sementara buzzer pasif yaitu buzzer yang mempunyai suara sendiri, dapat digunakan tinggi dan rendahnya nada. [12]

\subsection{Water pump}

Water Pump merupakan jenis pompa yang menggunakan motor dc dan tegangan searah sebagai sumber tenaganya. Dengan memberikan beda tegangan pada kedua terminal tersebut, motor akan berputar pada satu arah, dan bila polaritas dari tegangan tersebut dibalik maka arah putaran motor akan terbalik pula. Polaritas dari tegangan yang diberikan pada dua terminal menentukan arah putaran motor, sedangkan besar dari beda tegangan pada kedua terminal menentukan kecepatan motor Gaya elektromagnetik akan muncul pada motor DC saat terdapat arus yang mengalir pada penghantar medan magnet. Medan magnet itu sendiri ditimbulkan oleh megnet permanen. [13]

\subsection{Modul ESP826}

ESP8266 merupakan perangkat elektronik yang disebut juga dengan modul wifi. Modul ESP8266 sangat membantu sebagai alat bantu sistem agar lebih mudah terkomunikasi dengan internet, yang sering dikenal dengan Internet of Things. Ada banyak jenis ESP8266, salah satu yang sering digunakan adalah ESP-01. [14] 


\subsection{Sensor Flow Meter}

Flow meter adalah alat yang digunakan untuk mengukur aliran suatu zat cair atau gas dalam penampang tertentu. Pengukuran dengan flow meter akan menghasilkan nilai yang disebut 'flow rate' atau disebut 'debit' dengan satuan Liter per hours. Satuan ini kemudian bisa diturunkan menjadi $\mathrm{L} / \mathrm{m}$ (Liter per minutes) atau L/s (liter per second) sesuai kebutuhan. Dari besaran flow rate/debit ini jika dikalikan dengan waktu, akan menghasilkan nilai volume dalam 'liter' dengan rumus $\mathrm{V}=\mathrm{Q} \times \mathrm{T}$ dengan $\mathrm{V}$ adalah volume $(\mathrm{L})$, $\mathrm{Q}$ adalah debit air dalam satuan (L/s) dan $\mathrm{t}$ adalah waktu dalam satuan detik. [15]

\subsection{Relay}

Relay adalah Saklar (Switch) yang dioperasikan secara listrik dan merupakan komponen Electromechanical (Elektromekanikal) yang terdiri dari 2 bagian utama yakni Elektromagnet (Coil) dan Mekanikal (seperangkat Kontak Saklar/Switch). Prinsip Relay menggunakan Elektromagnetik untuk menggerakkan Saklar sehingga dengan arus listrik kecil (low power) dapat menghantarkan listrik yang bertegangan lebih tinggi. Sebagai contoh, dengan Relay yang menggunakan Elektromagnet $5 \mathrm{~V}$ dan 50 $\mathrm{mA}$ mampu menggerakan Armature Relay (yang berfungsi sebagai saklarnya) untuk menghantarkan listrik 220V 2A. [16]

\section{METODE PENELITIAN}

\subsection{Analisa Kebutuhan Fungsional}

Adapun beberapa kebutuhan fungsional dalam alat monitoring kualitas air dan sistem administrasi pada pengelola air bersih skala kecil antara lain :

Tabel 1.Kebutuhan Fungsional

\begin{tabular}{|l|l|c|}
\hline No. & \multicolumn{1}{|c|}{ Hardware } & \multicolumn{1}{c|}{ Software } \\
\hline 1. & Arduino Uno R3 & $\begin{array}{l}\text { Arduino IDE } \\
6.11\end{array}$ \\
\hline 2. & Modul ESP8266 & Visual Code \\
\hline 3. & Sensor pH air (pH meter) & Web browser \\
\hline 4. & Sensor Turbidity & XAMPP \\
\hline 5. & Sensor Flow meter & - \\
\hline 6. & Buzzer & - \\
\hline 7. & Relay & - \\
\hline 8. & Water pump mini & - \\
\hline
\end{tabular}

\subsection{Analisa Kebutuhan Non-Fungsional}

Adapun beberapa kebutuhan Non-fungsional dalam alat monitoring kualitas air dan sistem administrasi pada pengelola air bersih skala kecil antara lain:

1. Website monitoring dapat berjalan pada web browser

2. Datasheet yang digunakan merupakan hasil dari baca sensor

3. Website monitoring menggunakan server local

4. Website ini hanya memonitoring kualitas air.

\subsection{Diagram Blok Sistem}

Monitoring kualitas air dan sistem administrasi pada pengelola air bersih skala kecil menggunakan modul ESP8266 yang di kontrol menggunakan arduino uno. Arduino uno mendapatkan data yang diperoleh dari sensor $\mathrm{pH}$,turbidity dan flow meter. Data kadar $\mathrm{pH}$ dan kekeruhan yang di peroleh dari sensor $\mathrm{pH}$ dan turbidity dilakukan proses pengecekan melalui arduino selain pengecekan kadar $\mathrm{pH}$ air dan kekeruhan debit air yang keluar di perhitungkan , kemudian masuk kedalam database mamlalui bantuan komunikasi modul ESP8266 yang di tampilkan pada website kondisi air dan konversi dalam bentuk rupiah untuk tagihan air perbulannya. Apabila pengecekan menunjukan kondisi air buruk maka akan dilakukan penyaringan pada air. Diagram blok dapat dilihat pada Gambar 1.

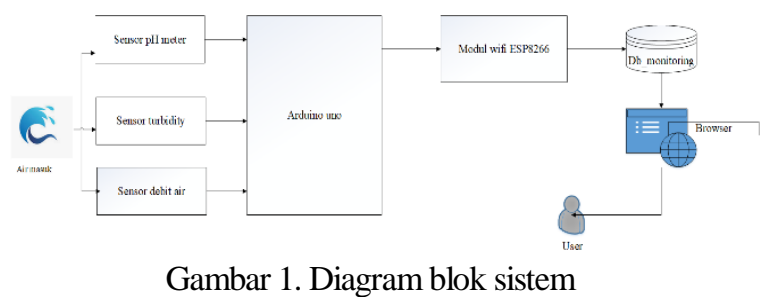

\subsection{Alokasi Pin}

Alokasi pin untuk sistem monitoring kualitas air dan sistem administrasi pada pengelola air bersih skala kecil.alokasi pin dapat dilihat pada Tabel 2.

Tabel 2. Alokasi pin sistem monitoring

\begin{tabular}{|l|l|c|c|c|c|c|}
\hline $\begin{array}{c}\text { Arduino } \\
\text { Uno }\end{array}$ & ESP8266 & $\begin{array}{c}\mathrm{pH} \\
\text { meter }\end{array}$ & Turbidity & Flow meter & relay & buzzer \\
\hline Vin & VCC/3.3V & VCC/5V & VCC/5V & VCC/5V & VCC/5V & VCC/5V \\
\hline GND & GND & GND & GND & GND & GND & GND \\
\hline Pin 3 & Rx & - & - & - & - & - \\
\hline Pin 4 & Tx & - & - & - & - & - \\
\hline Pin 5 & - & - & - & Data & - & - \\
\hline Pin 6 & - & - & - & - & - & Data \\
\hline Pin 8 & - & - & - & - & Data & - \\
\hline Pin A0 & - & - & Data & - & - & - \\
\hline Pin A1 & - & Data & - & - & - & - \\
\hline
\end{tabular}

\subsection{Struktur Menu Website}

Website monitoring kualitas air dan sistem administrasi pada pengelola air bersih skala kecil terdiri dari empat halaman utama yaitu halaman home data, data sensor $\mathrm{pH}$ dan grafik ,data sensor turbidty, dan data sensor Flow meter.Berikut stuktur menu pada website dapat dilihat pada Gambar 2

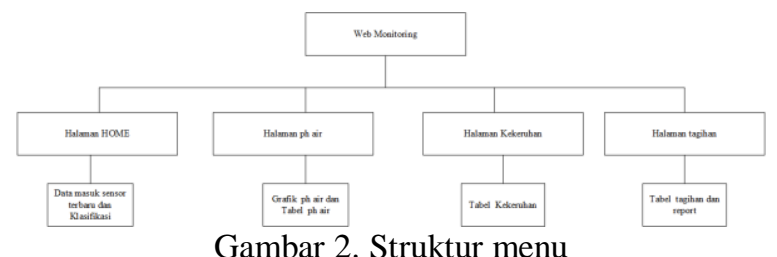




\subsection{Flowchart Sistem}

Desain arsitektur sistem menjelaskan alur dari berjalannya sistem monitoring kualitas air dan sistem administrasi pada pengelola air bersih skala kecil. Flowchart sistem bisa dilihat pada Gambar 3.

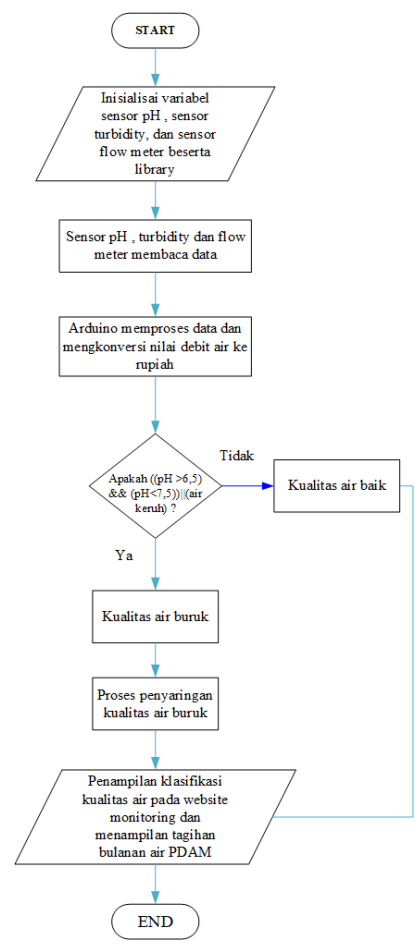

Gambar 3. Flowchart Sistem

\section{HASIL DAN PEMBAHASAN}

Pada bab ini akan ditunjukkan hasil dan pembahasan terhadap proses yang telah dilakukan.

\subsection{Pengujian Sensor pH meter}

Pengujian data Sensor $\mathrm{pH}$ membandingkan dengan perubahan warna kertas lakmus dengan data yang dibaca oleh sensor $\mathrm{pH}$ meter, seperti pada Tabel 3 .

Tabel 3. Pengujian Sensor $\mathrm{pH}$ meter

\begin{tabular}{|c|c|c|c|c|}
\hline No & $\begin{array}{c}\text { Jenis } \\
\text { larutan }\end{array}$ & Nilai $\mathrm{pH}$ & $\begin{array}{c}\text { Indikator } \\
\text { Lakmus }\end{array}$ & Indikasi \\
\hline 1 & Air Putih & $6-8$ & $\begin{array}{c}\text { warna hijau } \\
\text { muda ke } \\
\text { hijau agak } \\
\text { gelap }\end{array}$ & netral \\
\hline 2 & air sabun & $9-10$ & $\begin{array}{c}\text { hijau gelap } \\
\text { ke warna } \\
\text { hijau lebih } \\
\text { gelap lagi }\end{array}$ & basa \\
\hline 3 & Air Lemon & $3-5$ & $\begin{array}{c}\text { warna jingga } \\
\text { muda ke } \\
\text { kuning }\end{array}$ & asam \\
\hline 4 & Cuka & 2 & warna jingga & asam \\
\hline
\end{tabular}

Pada pengujian sensor $\mathrm{pH}$ meter membandingan perubahan warna dengan menggunakan kertas lakmus. Pada pengujian air putih atau air mineral nilai $\mathrm{pH}$ yang di tangkap sensor sekitar 6-8 sedangkan pada kertas lakmus mengalami perubahan warna hijau ke hijau agak gelap dengan indikasi kondisi netral. Pada pengujian air sabun nilai $\mathrm{pH}$ air yang di tangkap sekitar 9-10 sedangkan pada kertas lakmus berubah warna dari warna hijau ke warna hijau lebih gelap lagi di bandingkan dengan warna kertas lakmus air putih dengan indikasi kondisi $\mathrm{pH}$ basa. Pada pengujian air lemon nilai $\mathrm{pH}$ air yang didapat sekitar 3-5 sedangkan pada kertas lakmus berubah warna dari warna jingga muda ke kuning dengan indikasi kondisi $\mathrm{Ph}$ asam. Sedangkan pada air cuka didapat kan nilai $\mathrm{pH} 2$ dengan warna kertas lakmus jingga indikator $\mathrm{pH}$ asam.

\subsection{Pengujian Sensor Turbidity}

Pengujian data sensor Turbidity ini dilakukan dengan mengkalibrasi sensor dengan memasukan sensor kebeberapa jenis air. Pertama kedalam air putih bersih, selanjutnya celupkan sensor turbidity ini ke beberapa sempel air dan hasil pembacaan nilai kekeruhannya. Dapat dilihat pada Tabel 4.

Table 4. Pengujian Sensor Turbidity

\begin{tabular}{|c|c|c|c|c|}
\hline No & $\begin{array}{c}\text { Jenis } \\
\text { larutan }\end{array}$ & $\begin{array}{c}\text { Nilai } \\
\text { kekeruhan }\end{array}$ & Datasheet & $\begin{array}{c}\text { Persentasi } \\
\text { error }\end{array}$ \\
\hline 1 & Air & 2.5 & 2.56 & $0.98 \%$ \\
\hline 2 & Teh & 2.73 & 3.37 & $0.81 \%$ \\
\hline 3 & kopi & 7.14 & 5.03 & $1.45 \%$ \\
\hline
\end{tabular}

Pada pengujian sensor turbidity atau sensor pendeteksi kekeruhan dengan mengkalibarasikan dengan beberapa jenis air seperti air biasa, teh, dan kopi. Pengujian ini membandingkan dengan datasheet sensor turbidty. Untuk air mineral sensor turbidity menagkap nilai 2.5 NTU sedangkan pada datasheet 2.56 persentasi nilai error perbandingannya sekitar $0.98 \%$. Untuk teh sensor turbidity menangkap nilai 2.73 NTU sedangkan pada datasheet 3.37 persentasi nilia error perbandingan sekitar $0.81 \%$. dan pada kopi nilai kekeruhan yang di tangkap sensor turbidity 7.14 NTU sedangkan pada datasheet sensor 5.03 persentasi error nilai error perbandingan sekitar $1.45 \%$.

\subsection{Pengujian Sensor Flow Meter}

Pengujian debit air ini dilakukan dengan cara membandingkan tampilan nilai debit yang ada di serial monitor dengan perhitungan debit manual. Dapat dilihat pada Tabel 5 . 
Tabel 5. Pengujian Sensor Flow Meter

\begin{tabular}{|c|c|c|c|}
\hline No & $\begin{array}{c}\text { Pembacaan } \\
\text { debit } \\
\text { arduino }\end{array}$ & $\begin{array}{c}\text { Perhitungan } \\
\text { Manual }\end{array}$ & $\begin{array}{c}\text { Persentasi } \\
\text { error }\end{array}$ \\
\hline 1 & 5.1 & 5.5 & $0.4 \%$ \\
\hline 2 & 5.3 & 5.75 & $0.45 \%$ \\
\hline 3 & 5.1 & 6.32 & $1.22 \%$ \\
\hline 4 & 5.1 & 5.5 & $0.93 \%$ \\
\hline 5 & 5.3 & 5.5 & $0.2 \%$ \\
\hline 6 & 5.3 & 5.75 & $0.45 \%$ \\
\hline 7 & 5.0 & 5.3 & $0.3 \%$ \\
\hline 8 & 5.1 & 5.5 & $0.4 \%$ \\
\hline 9 & 5.1 & 5.3 & $0.2 \%$ \\
\hline 10 & 5.3 & 5.5 & $0.2 \%$ \\
\hline \multicolumn{3}{|c|}{ Rata-rata persentasi error } \\
\hline
\end{tabular}

Pada pengujian sensor flow meter dilakukan perbandingan dengan data yang ditangkap sensor dengan data perhitungan debit manual. Dengan data yang di tangkap sensor flow meter $5.1,5.3,5.1,5.1$ dengan perhitungan manual yang di dapat $5.5,5.75$ ,6.32, 5.5 dengan persentasi error data pertama $0.93 \%$ , data kedua $0.92 \%$, data ke tiga $0.81 \%$ dan data ke empat $0.93 \%$.

\subsection{Pengujian ESP8266}

Pengujian pada modul ESP8266 disebut modul wifi menggunakan pengujian pengiriman data dari sensor Ke web server.Dapat dilihat pada Tabel 6.

Tabel 6. Pengujian ESP8266

\begin{tabular}{|c|c|c|c|}
\hline \multirow{2}{*}{ No } & \multicolumn{2}{|c|}{ waktu } & \multirow{2}{*}{ delay(detik) } \\
\cline { 2 - 3 } & pengiriman & tampil pada website & \\
\hline 1 & $15: 10: 56$ & $15: 11: 09$ & 15 \\
\hline 2 & $15: 13: 32$ & $15: 13: 47$ & 15 \\
\hline 3 & $15: 14: 17$ & $15: 14: 32$ & 15 \\
\hline 4 & $15: 04: 27$ & $15: 04: 42$ & 15 \\
\hline
\end{tabular}

Dari Tabel 6 dapat diamati bahwa delay pada pengiriman data sudah sesuai yaitu 15 detik. Delay dibuat 15 detik untuk menjaga komponen agar tetap bekerja dengan optimal

\subsection{Pengujian alat monitoring kualitas air}

Pada alat sistem monitoring kualitas air dan sistem administrasi pada pengelola air bersih skala kecil dilakukan pengujian terhadap kinerja sistem yang ada baik kinerja komponen maupun kinerja dan eksekusi program yang telah dibuat. Bentuk alat dapat dilihat pada Gambar 4 Tabel 7 pengujian alat.

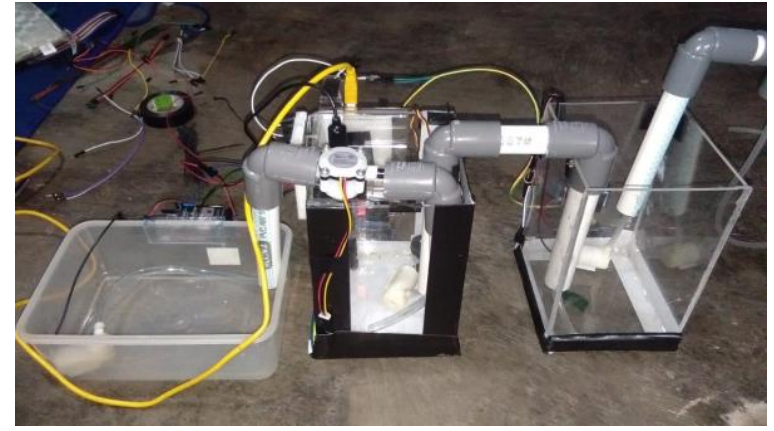

Gambar 4. Alat sistem monitoring kualitas air dan sistem administrasi

Tabel 7. Pengujian alat

\begin{tabular}{|c|c|c|c|c|c|}
\hline No & $\begin{array}{c}\text { Nama } \\
\text { Komponen }\end{array}$ & Jumlah & $\begin{array}{c}\text { Tegangan yang } \\
\text { dibutuhkan }\end{array}$ & $\begin{array}{c}\text { Berfungsi } \\
\text { dengan baik }\end{array}$ & $\begin{array}{c}\text { Mempunyai } \\
\text { masalah atau } \\
\text { trouble }\end{array}$ \\
\hline 1 & ESP8266 & 1 & $3.3 \mathrm{~V}$ & $\sqrt{ }$ & $\mathrm{x}$ \\
\hline 2 & $\begin{array}{c}\text { Sensor } \mathrm{pH} \\
\text { meter }\end{array}$ & 1 & $5 \mathrm{v}$ & $\sqrt{ }$ & $\mathrm{x}$ \\
\hline 3 & Turbidity & 1 & $5 \mathrm{v}$ & $\sqrt{ }$ & $\mathrm{x}$ \\
\hline 4 & Flow meter & 1 & $5 \mathrm{v}$ & $\sqrt{ }$ & $\mathrm{x}$ \\
\hline 5 & Relay & 3 & $5 \mathrm{v}$ & $\sqrt{ }$ & $\mathrm{x}$ \\
\hline 6 & Buzzer & 1 & $5 \mathrm{v}$ & $\sqrt{ }$ & $\mathrm{x}$ \\
\hline 7 & Water pump & 3 & $5 \mathrm{v}$ & $\sqrt{ }$ & $\mathrm{x}$ \\
\hline \multicolumn{7}{|c}{ Tegangan yang dibutuhkan } & $33.3 \mathrm{v}$ \\
\hline
\end{tabular}

Keterangan :

$\sqrt{ }=$ berhasil

$\mathrm{X}=$ tidak berhasil

Pada pengujian hardware pada Tabel 6, maka dapat dilihat bahwa jenis-jenis alat atau hardware pada sistem pendeteksian kualitas air berjalan dengan baik. Seperti modul untuk komunikasi data ESP8266, sensor $\mathrm{pH}$ meter, sensor turbidity, sensor flow meter, relay, buzzer dan water pump berjalan sesuai fungsi dengan baik. Untuk sumber daya untuk alat menggunakan power supply agar bisa digunakan 24 jam.

\subsection{Pengujian Browser}

Pengujian software merupakan pengujian kompabilitas website terhadap beberapa web browser. hasil ujinya dapat dilihat di Tabel 7

\begin{tabular}{|c|c|c|c|c|}
\hline \multirow[b]{2}{*}{ No } & \multirow[b]{2}{*}{ Aspek Pengujian } & \multicolumn{3}{|c|}{ Web Browser } \\
\hline & & Mozila (83.0) & Chrome (86.0) & $\begin{array}{c}\text { Microsoft } \\
\text { Edge (87.0) }\end{array}$ \\
\hline 1 & $\begin{array}{l}\text { card data sensor pada } \\
\text { halaman utama }\end{array}$ & $\sqrt{ }$ & $\sqrt{ }$ & $\sqrt{ }$ \\
\hline 2 & $\begin{array}{l}\text { tampilan Gambar pada } \\
\text { halaman utama }\end{array}$ & $\sqrt{ }$ & $\sqrt{ }$ & $\sqrt{ }$ \\
\hline 3 & Tampilan halaman $\mathrm{pH}$ air & $\sqrt{ }$ & $\sqrt{ }$ & $\sqrt{ }$ \\
\hline 4 & $\begin{array}{l}\text { Tampilan halaman } \\
\text { Kekeruhan }\end{array}$ & $\sqrt{ }$ & $\sqrt{ }$ & $\sqrt{ }$ \\
\hline 5 & $\begin{array}{l}\text { Tampilan halaman } \\
\text { Tagihan }\end{array}$ & $\sqrt{ }$ & $\sqrt{ }$ & $\sqrt{ }$ \\
\hline 6 & $\begin{array}{l}\text { tampilan grafik pada } \\
\text { halaman } \mathrm{pH} \text { air }\end{array}$ & $\sqrt{ }$ & $\sqrt{ }$ & $\sqrt{ }$ \\
\hline 7 & $\begin{array}{l}\text { tampilan data pada tabel } \\
\text { tiap sensor }\end{array}$ & $\sqrt{ }$ & $\sqrt{ }$ & $\sqrt{ }$ \\
\hline 8 & $\begin{array}{l}\text { fungsi report pada } \\
\text { halaman tagihan }\end{array}$ & $\sqrt{ }$ & $\sqrt{ }$ & $\sqrt{ }$ \\
\hline 9 & $\begin{array}{l}\text { pagination pada tampilan } \\
\text { data tabel }\end{array}$ & $\sqrt{ }$ & $\sqrt{ }$ & $\sqrt{ }$ \\
\hline
\end{tabular}

Keterangan :

$\sqrt{ }$ : iya

$\mathrm{X}$ : Tidak 
Pada pengujian software terhadap kompabilitas website terhadap beberapa web browser. Setiap bagian pada website seperti card data sensor pada halaman utama, tampilan Gambar pada halaman utama, Tampilan halaman $\mathrm{pH}$ air, Tampilan halaman Kekeruhan, Tampilan halaman Tagihan, tampilan grafik pada halaman $\mathrm{pH}$ air, tampilan data pada Tabel tiap sensor, fungsi report pada halaman tagihan, pagination pada tampilan data Tabel semua fungsi pada website berjalan dengan baik pada web browser Mozila firefox, chrome, dan Microsoft Edge. Pada Microsoft Edge hanya tampilan Gambar sedikit lebih lama untuk tampil pada saat menjalankan website monitoring

\subsection{Tampilan Halaman Utama}

Pada halaman utama digunakan untuk memonitoring data sensor yang masuk secara realtime termasuk nilai $\mathrm{pH}$, kekeruhan dan tagihan air secara berkala dapat dilihat pada Gambar 5.

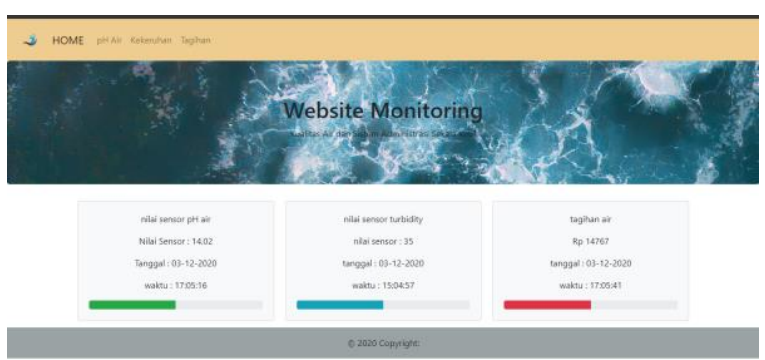

Gambar 5 Tampilan Halaman Utama

\subsection{Tampilan Halaman $\mathrm{pH}$ air}

Pada halaman $\mathrm{pH}$ air dapat dilihat grafik kualitas $\mathrm{pH}$ air dan tabel data $\mathrm{pH}$ air yang masuk secara realtime, dapat dilihat pada Gambar 6.

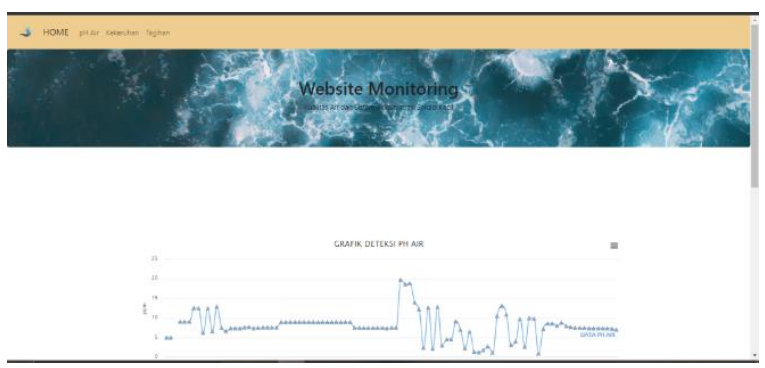

Gambar 6 Tampilan Halaman pH air

\subsection{Tampilan Halaman Kekeruhan}

Pada halaman kekeruhan menampilkan data kekeruhan yang diambil dari sensor turbidity sebagai pembaca kekeruhan air dan ditampilkan dalam bentuk table dari data yang didapat secara realtime. Dapat dilihat pada Gambar 7.

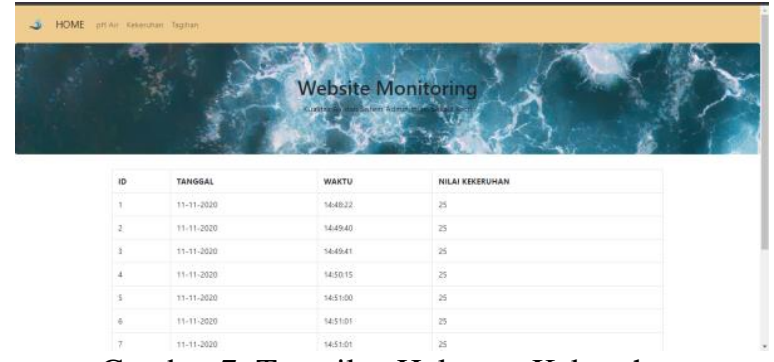

Gambar 7 Tampilan Halaman Kekeruhan

\subsection{Tampilan Halaman Tagihan}

Pada halaman tagihan menampilkan data tagihan penggunaan air yang di ambil dari data yang di dapat dari sensor flow meter berupa debit air yang kemudian di ubah dalam perhitungan penggunaan air, dan terdapat tombol report untuk mencetak data. dapat dilihat pada Gambar 8.

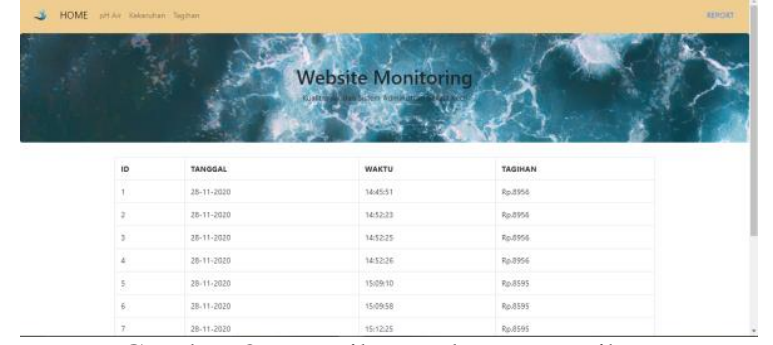

Gambar 8 Tampilan Halaman Tagihan

\section{KESIMPULAN DAN SARAN}

\subsection{Kesimpulan}

Dengan adanya implementasi IoT (internet of things) monitoring kualitas air dan sistem administrasi pada pengelola air bersih skala kecil yang telah penulis buat dapat di ambil kesimpulan :

1. Sistem yang dibuat dapat memonitoring kualitaas $\mathrm{pH}$ air nilai 7.00 untuk air mineral, air lemon 5.9, air sabun 10.4, dan dengan indikasi lakmus dalam penentuan asam basa pada air, kekeruhan air persentasi pengujian terbesar $1.45 \%$, dan debit air yang masuk beserta tagihan air pada rumah warga.

2. Komunikasi sistem menggunakan modul wifi ESP8266 untuk send data pada web sever dari jarak jauh, menggunakan konsep IoT

3. Website monitoring kualitas air dan sistem administrasi skala kecil dapat berjalan di browser Mozila Firefox, Google Chrome, Microsoft edge. Tapi pada web browser Microsoft edge masih tidak stabil menampilkan Gambar background

\subsection{Saran}

Adapun saran untuk melanjutkan penelitian dan perbaikan kedepannya sebagai berikut:

1. Alat Monitoring Pendeteksi Kualitas Air dan Pengelolaan Administrasi Sekala Kecil masih memerlukan pengembangan lebih lanjut agar sistem pintar lebih baik lagi dan dapat di kembangkan untuk penggunaan masal, untuk penelitian selanjutnya. 
2. Pada alat untuk penelitian selanjutnya dapat digunakan alat yang lebih terbaru agar data baca sensor lebih akurat.

\section{DAFTAR PUSTAKA}

[1] S. P. D. I. Suryo Adi Wibowo, "EARLY WARNING SYSTEM FOR BUILDING AUTOMATION SYSTEM," Jurnal Teknologi Informas, vol. 06, no. 02, 2015.

[2] Y. Dewi Lestari, "Perancangan Alat Pembacaan Meter Air PDAM Menggunakan," vol. 01, no. 02, 2018.

[3] S. A. Kurniatuty, "Rancang Bangun Sistem Kontrol Pakan Ikan dan Kekeruhan Air yang Dilengkapi Dengan Monitoring Kualitas Air Berbasis Internet of Things (IoT)," 2019.

[4] S. A. Y. Ummi Syafiqoh, "Pengembangan Wireless Sensor Network Berbasis Internet of Things untuk Sistem Pemantauan Kualitas Air dan Tanah Pertanian," Jurnal Informatika: Jurnal Pengembangan IT (JPIT, vol. 03, no. 02, 2018.

[5] T. U. K. Y. S. H. Diko Susanto, "ALAT PENYARINGAN AIR KOTOR MENJADI AIR BERSIH MENGGUNAKAN MIKROKONTROLLER ATMEGA 32," Jurnal Media Infotama, vol. 10, no. 02, 2014.

[6] M. Shidiq, "Menara Ilmu Otomasi Departemen Teknik Elektro dan Informatika Sekolah Vojasi Universitas Gadjah Mada," Universitas Gadjah Mada, 02 Juni 2018. [Online]. Available: https://otomasi.sv.ugm.ac.id/2018/06/02/penger tian-internet-of-things-iot/. [Diakses 31 Agustus 2020].

[7] P. I. C. T. Tony D. Susanto, SMART CITY:KONSEP, MODEL, \& TEKNOLOGI, Surabaya: Asosiasi Sistem Informasi Indonesia (AISINDO), 2019.

[8] B. Renaldi, "RANCANG BANGUN ROBOT SAR SEBAGAI PENDETEKSI GAS BERACUN PRA EVAKUASI," JATI, vol. 3, no. 5, 2019.

[9] S. Giri Wahyu Pambudi, Belajar Arduino from Zero to Hero (jilid 1), Eromoko, Wonogiri: cronyos.com, 2020.
[10] A. Faudin, "nyebarilmu.com," nyebailmu.com, 13 April 2019. [Online]. Available: https://www.nyebarilmu.com/tutorialmengakses-module-ph-meter-sensormenggunakanarduino/\#: :text=Modul\%20sensor\%20ini\%20 merupakan\%20module,di\%20kode\%20progra m\%20yang\%20dibuat.. [Diakses 13 April 2020].

[11] Uknown, "Digiware.com," [Online]. Available: https://digiwarestore.com/id/sensorother/analog-turbidity-sensor-for-arduino296297.html. [Diakses 01 September 2020].

[12] M. syefudin, "Cara Menggunakan Buzzer pada Arduino Uno," indomaker.com, 29 Desember $2019 . \quad$ [Online]. Available: http://indomaker.com/index.php/2018/12/29/car a-menggunakan-buzzer-pada-arduinouno/\#: :text=Buzzer\%20merupakan\%20kompo nen $\% 20$ elektronika\%20yang,untuk\%20keperlu an\%20notifikasi\%20atau\%20pemberitahuan.\&t ext=Sekarang\%20mari\%20kita\%20coba\%20m enggunakan,dengan\%2. [Diakses 29 September 2020].

[13] S. A. W. ,. H. Z. Z. Dimas Adi Pratama, "PENGAIRAN DAN PEMBERIAN PAKAN OTOMATIS PADA AKUARIUM BERBASIS ARDUINO," 2018.

[14] C. Anam., EBOOK ESP8266, Indramayu: WWW.ANAKKENDALI.COM.

[15] ajie, "Saptaji.com," SAPTAJI.COM, 15 Agustus 2016. [Online]. Available: http://saptaji.com/2016/08/15/mengukur-debitdan-volume-air-dengan-flow-meter-danarduino/. [Diakses 27 September 2020].

[16] D. Kho, "Pengertian Relay dan Fungsinya," Teknik Elektronika, [Online]. Available: https://teknikelektronika.com/pengertian-relayfungsi-relay/. [Diakses 29 Oktober 2020].

[17] M. Riadi, "Smart City (Pengertian, Karakteristik, Indikator dan Penerapan)," KajianPustaka.com, 17 Januari 2020. [Online]. Available:

https://www.kajianpustaka.com/2020/01/smartcity-pengertian-karakteristik-indikator-danpenerapan.html. [Diakses 28 Oktober 2020]. 